\title{
GIS based land use planning and watershed monitoring as tools for sustainable development
}

\author{
J. Alonso ${ }^{1}$, J. Rey $^{1}$, P. Castro ${ }^{2} \&$ C. Guerra ${ }^{1}$ \\ ${ }^{l}$ Escola Superior Agrária, Instituto Politécnico de Viana do Castelo, \\ Mosteiro de Reifóios do Lima, Ponte de Lima, Portugal \\ ${ }^{2}$ Escola Superior Tecnologia e Gestão, \\ Instituto Politécnico de Viana do Castelo, Viana do Castelo, Portugal
}

\begin{abstract}
The development of GIS based methodologies supports a program for monitoring the territorial dynamics that are occurring in the Estorãos rural watershed (NW Portugal). GIS integrates spatial databases from different research and development projects, with the purpose of understanding: (i) the relationships between land use processes and changes, and environmental management policies; (ii) the extent of environmental impacts due to forest fire as well as extending and intensifying agriculture; and (iii) the influences of natural conditions and human activities on water quality and ecosystem sustainability. The diversity of natural conditions and population dynamics, the (de)forestation, the expansion, density and typology of road networks, the processes of urbanization in the flood plain, and the rising turistic search from external actors, fundament the importance of a GIS based watershed monitoring program. These conditions and processes increase watershed management complexity, namely at a protected wetland in the bottom valley (regional protected landscape, site PTCON00020 of Natura Network 2000, and international RAMSAR site 1613) related to the structure of the landscape, and the quantity and quality of the water resources and the associated biodiversity. The challenges of sustainable land use and the growing quantity and quality of the available spatial databases, allow greater modelling capacity and data accessibility, facilitating public participation, and also aiding and better guiding political and technical actions.

Keywords: spatial decision support system, watershed, geographic information systems, landscape planning and management.
\end{abstract}




\section{Introduction}

Global impacts of earth's human population are reflected in extensive changes in the spatial patterns of land cover and land use [5, 6]. In this sense, land use and landscape dynamics result from the decisions and actions undertaken by humans in the context of: a) natural conditions; b) access to scientific and technological knowledge; c) sectorial and territorial policies; and d) historical constraints.

Although Turner et al. [2] didn't include a human component explicitly in the definition of landscape ecology, this work follows a more inclusive view [3] that concerns itself not just with biophysical processes, but also with human actions that shape the landscape [1]. This study pretends an appropriate view of management interventions following the emerging concepts of "integrated land science" [4]. Despite the fact that this term is most often associated with regional or larger scales, land use planning occurs at different spatial scales [7] being applied to smaller scales, e.g. the farm level, where farmers have to plan their land use and cover considering contrasting economic and environmental requirements [7].

Landscape dynamics and land cover processes can be described in a variety of ways, regarding different models and theoretical views. In this sense, researchers are approaching these concerns from a landscape ecology perspective [9] or by using the advances in geographic information science [8, 10]. These different perspectives, when converged, assume an important role in the options made by managers and planners at different scales and information levels. In this context the landscape acts as a focus for integrating human and environmental processes [11]. Monitoring its components and changes is the basis to understanding environmental and human dynamics.

\section{Environmental monitoring systems and rural landscapes}

Land resource management requires merging of data and knowledge based networks from many different areas of expertise [12]. According to Matthews et al. [13], managers seek more information according to factors regarding economic competition, land use regulation, public awareness, and land ownership changes. This demand for multiple objective land use planning requires more information (in quantity and quality) to allow managers to explore and test different proposals and strategies.

In this way, the development of an environmental monitoring system (EMS) can integrate valuable information of processes, structures, and environmental variables, permitting the analysis and modelling of the territory characteristics and dynamics.

Rural landscapes in Europe [14], as well as in the NW Portugal, are in both homogenisation and fragmentation processes. These processes can act at multiple scales and have different intensity and dimension. An EMS can then be crucial to identify and understand the occurring changes and their relative dimensions, directing land management options and supporting technical as well as political decisions. 
A key factor for sustainability is to develop links across multiple levels of decision making $[15,16]$. According to Joerin and Musy [25] in order to achieve the new European approaches to land management, managers need efficient information processing tools and reliable decision support methods. In this context, an EMS should: a) take into account various levels of information; b) produce cohesive and structured data; and c) report consistent results in order to conduce and fundament future decisions.

An EMS supported by a GIS, returns an integrated system that can support and increase community commitment in the decision making process, leading to stronger, participated, responsible and well accepted decisions.

\subsection{Monitoring rural spaces: building trust in decision processes}

Rural spaces are diverse and dynamic systems that produce a set of specific environmental issues, and have their own distinct development process. In densely populated Europe, very few pristine natural areas exist [26]. The resulting cultural landscapes [28] aggregate many types of semi natural ecosystems, nevertheless characterized by high species richness, that depend on human interference for their persistence [26].

Complex and pressing environmental problems tend to expose the gaps in technologies, theories and scientific knowledge [29]. In this sense, rural environments have to be faced and analysed carefully in order to prevent rushed conclusions. Monitoring these spaces can be a methodological challenge for both scientists, resulting in better data analysis methods, and technicians, for data collection and quality controls.

These agri-environments are a result of cultural and natural heritage, dynamic equilibrium processes, and a set of constantly shifting ecotones. As well as in other spaces, ecological conservation has to be dynamic and has to integrate all local and regional stakeholders, in order to facilitate the negotiation precess. In these changing environments, issues like pollution control, ecosystem services and increasing biodiversity must be addressed by landscape managers [24].

In order to create these dynamic, decision making, environments, farmers and local communities should be included since the beginning of the processes. The benefits of broad-based community involvement in planning and design are widely documented [18], they include enhancing the capacity of citizens to cultivate a stronger sense of commitment, increasing user satisfaction, creating realistic expectations of the outcomes, and building trust (e.g. [19-23]).

\section{Methods}

A natural unit was selected that can be representative of the NW of the Iberian Peninsula, with the objective of monitoring the causes and consequences of the territorial dynamics. Watershed analysis and management are developing as tools of integrated ecological and economic studies [30], in this sense, a small watershed was selected (fig. 1) in order to facilitate the development of different and diverse studies. 

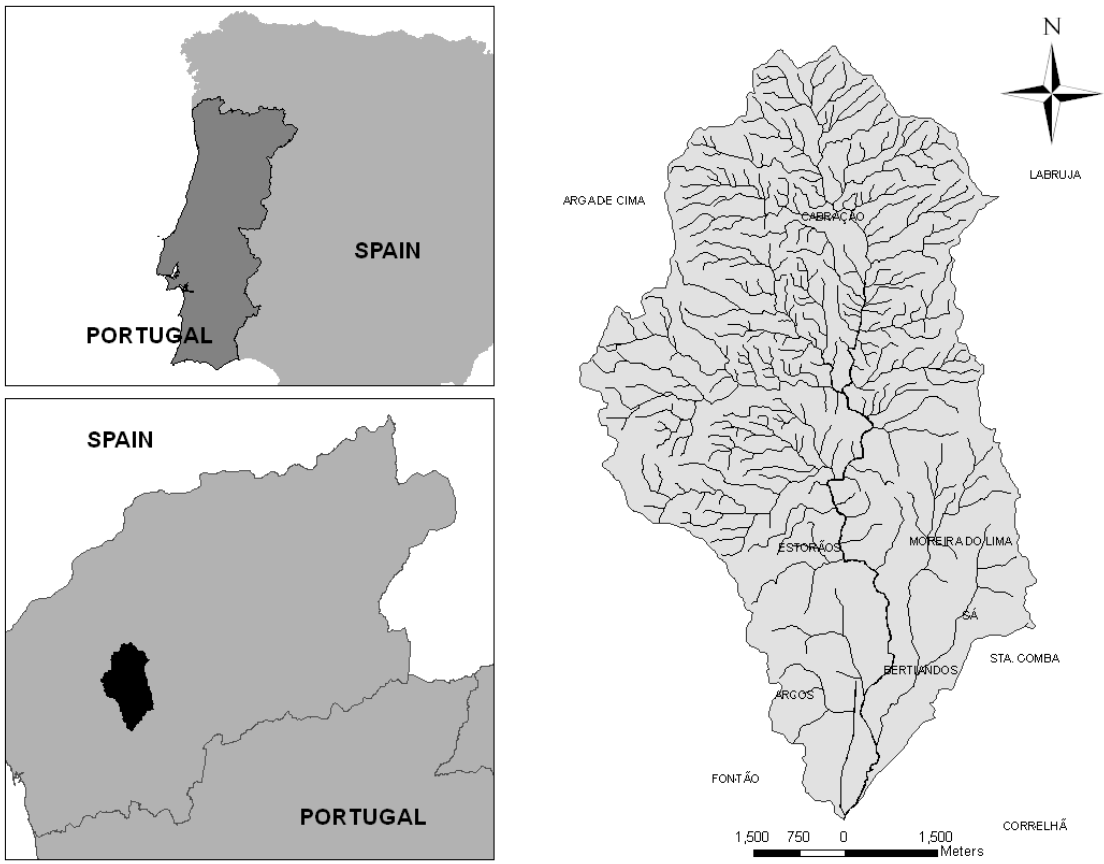

Figure 1: Geographic location of the Estorãos watershed.

\section{Actors}

\begin{tabular}{|c|}
\hline $\begin{array}{l}\text { Technicians } \\
\text { Scientists }\end{array}$ \\
\hline $\begin{array}{l}\text { Technicians } \\
\text { Technical advisers } \\
\text { Political decisors } \\
\text { Scientists }\end{array}$ \\
\hline $\begin{array}{l}\text { Technicians } \\
\text { Scientists } \\
\text { Population } \\
\text { Users } \\
\text { Decisors }\end{array}$ \\
\hline
\end{tabular}

\section{Processes and steps}

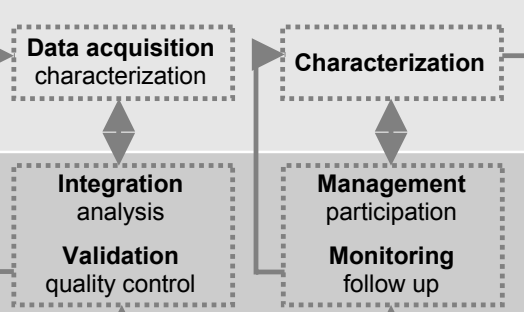

Edition

\section{Factors}

\section{Land Characteristics}

biophysical and human

-Information access and quantity

-Technical (in)formation

-Initial investment

\section{Land Functioning}

activities and dynamics

-Environmental conservation

-Teaching and investigation

-Economic activities

\section{Communication}

participation and decision

-Target groups

Promotion

-Information channels

-Success indicators

Figure 2: Actors, processes, steps and factors in the creation of a GIS for landscape characterization and analysis.

The development of the EMS, merged with an information system, took into account different processes of data capture, integration of different spatial databases, scientific studies, technical reports and proposals, the development and participation in regional forums, and the technical support of management decisions (fig. 2). 
The process of data capture was realized over a period of several years and took into account data collected from remote sensing, geographical analysis, field surveys, and specific studies. Information was then integrated into structured spatial databases, permitting the realization of technical and scientific reports.

As stated above, these spatial databases are usually constructed with information related to land use and cover, administrative limits, road networks, some other base information (e.g. geology, soils, altimetry), and derived thematic bases. In this specific case this information was complemented with others of particular interest (e.g. soil suitability, water quality networks, protection and environmental interest).

Regarding the presence of a protected wetland (regional protected landscape, site PTCON00020 of Natura Network 2000, and international RAMSAR site 1613 ) at the valley bottom, the geographical information of this particular area was improved in terms of resolution and quantity (table 1).

Table 1: Thematic information used to construct the environmental monitoring system.

\begin{tabular}{|c|c|c|}
\hline Thematic information & Source & Thematic scale \\
\hline \multicolumn{3}{|l|}{ Base Geographic Information } \\
\hline Administrative and natural limits & CMPL \& ESA-IPVC & Watershed \\
\hline Slope & ESA-IPVC & Watershed \\
\hline Altimetry & ESA-IPVC & Watershed \\
\hline Hidrography & ESA-IPVC & Watershed \\
\hline Solar exposures & ESA-IPVC & Watershed \\
\hline Land elevation models & ESA-IPVC & Watershed \\
\hline Toponymic information & ESA-IPVC & Watershed \\
\hline \multicolumn{3}{|l|}{ Geology and Soils } \\
\hline Geomorphology & DRAEDM & Watershed \\
\hline Soil types & DRAEDM & Watershed \\
\hline Soil suitability & DRAEDM & Watershed \\
\hline Land aptitude & DRAEDM & Watershed \\
\hline Edaphic parameters ( $\mathrm{pH}$, condutivity, $\mathrm{K}_{2} \mathrm{O}$, Na, etc.) & ESA-IPVC & Protected area \\
\hline \multicolumn{3}{|l|}{ Land Cover and Habitats } \\
\hline Land cover $(1958,1990,2000,2002,2004)$ & ESA-IPVC & Watershed \\
\hline Conservation areas & CMPL & Watershed \\
\hline MEDWET habitats & CMPL & Protected area \\
\hline \multicolumn{3}{|l|}{ Infrastructures } \\
\hline Road network & CMPL & Watershed \\
\hline Observation posts & CMPL & Protected area \\
\hline Pedestrian courses & CMPL & Protected area \\
\hline \multicolumn{3}{|l|}{ Land information system } \\
\hline Cadastral surveys & $\begin{array}{l}\text { CMPL, DRAEDM \& ESA- } \\
\text { IPVC }\end{array}$ & Protected area \\
\hline \multicolumn{3}{|l|}{ Complementary information } \\
\hline Water quality network & ESA-IPVC & Watershed \\
\hline Sub-watersheds limits & ESA-IPVC & Watershed \\
\hline Aquatic biodiversity network & ESA-IPVC & Watershed \\
\hline
\end{tabular}

The processes of capture and organization of the information were summated to quality controls regarding their compatibility, systematic, structure, and potential end-users. Managing these complex databases corresponds to a critical phase of the process. Questions related to information, technological 
interoperability and the consistence of the results and the management of different actors with diverse objectives, are always present and can create bias to the achievement of the project goals.

\section{Results}

Landscapes can be defined by their structure, function and change [27]. In this study analyses were made to identify each of these features regarding land cover change and its relation to natural conditions (e.g. geology, soils, slope). For the past few years, several studies and development projects were executed leading to a diversified group of results. These results include information about environmental risk evaluation, land planning, decision support systems, natural and demographic characteristics, and specific studies (e.g. [31-34]).

These studies helped managers to improve their work by indicating integrated and sustainable alternatives for land and water quality management, environmental dynamic conservation in agricultural areas, creating new social and economic dynamics in rural spaces, and to prevent natural and human risks (e.g. forest fire and other environmental degradation phenomena) [34]. All this data and information had to be organized in a systematic way in order to (fig. 3): a) determine who inputs the data and how is it inputted into the system; b) structure a spatial database that integrates all information making it possible to cross-reference all the data that has been inputted, in order to produce reports and other scientific studies; and c) improve the connections between local stakeholders and reduce the time and the effort to know "when to do" and "where to act".

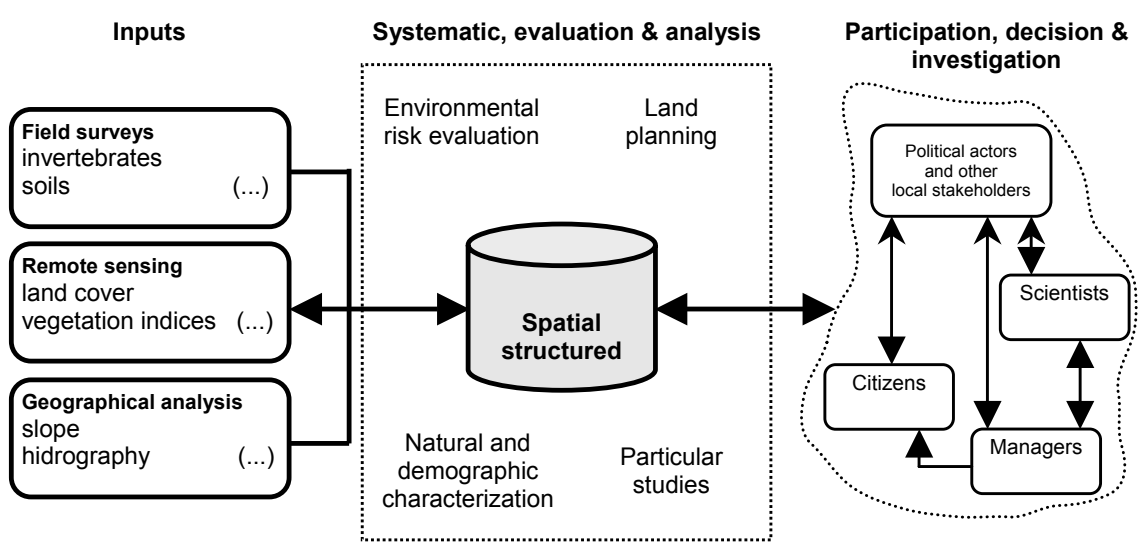

Figure 3: Method of construction and organization of the environmental monitoring system.

For some environmental and human features, namely land cover, forest fire and erosion risk, and water quality, it was possible to create a set of spatial analyses in order to contribute to a better planning procedure (fig. 4). 


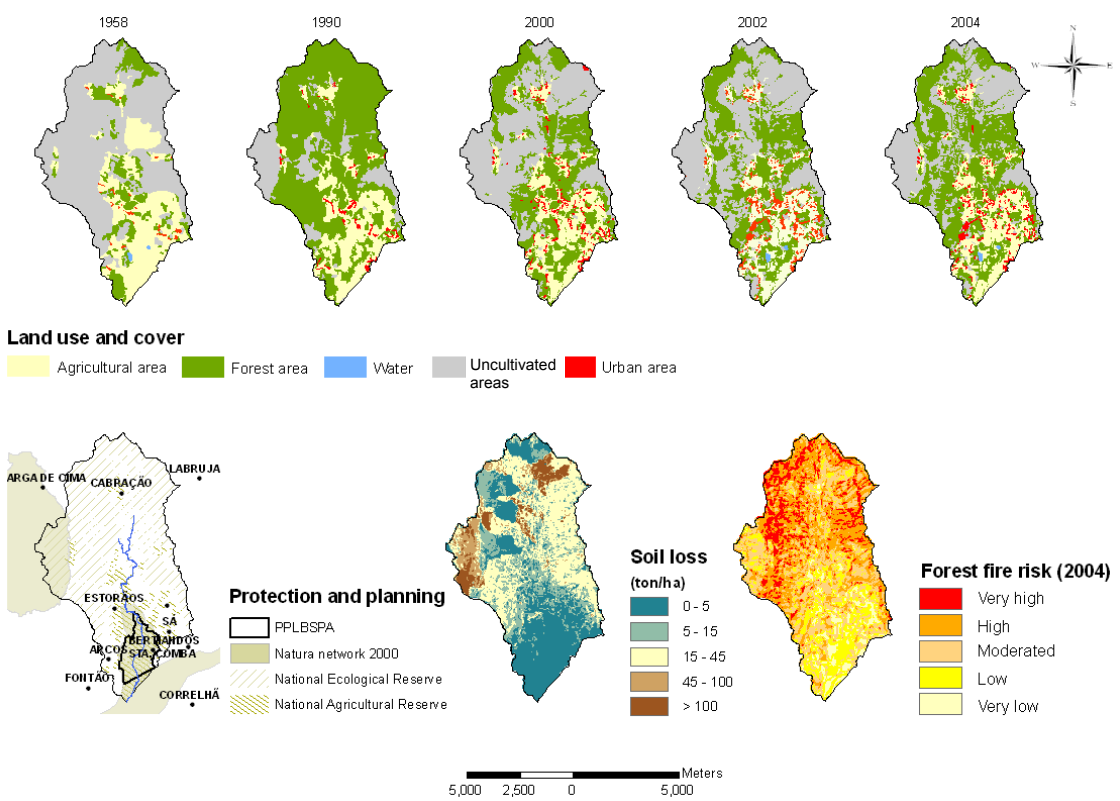

Figure 4: Examples of information used in the environmental monitoring system: land use and cover (top), protection areas and planning limits (left bottom), and environmental risks (right bottom).

\section{Discussion}

This environmental monitoring system (EMS) has combined a major group of valuable and reliable information, creating a capable spatial decision support system.

With this spatial decision support system it was possible to:

a) help the management of a regional protected area;

by providing tools for improving the interaction between decision makers and the local population and guaranteeing correct and precise descriptions of the local diversity.

b) promote the region and this particular area;

by publishing reports, books and scientific papers, by participating in forums, conferences and other public events, and by using a web based GIS.

c) promote investigation;

by integrating multi-disciplinary teams from different institutions and multiobjective studies.

d) develop environmental risk assessments;

by conducting field experiments and laboratory tests in order to present management alternatives.

e) improve the quantity and quality of data at the disposal of decision makers and the society; 
by gathering and structuring information into "user friendly" open access spatial databases.

f) help implementing policies to improve the quality of life of the general population;

by producing technical reports addressing a diversified group of management and planning issues at both regional and local scales.

In the future, the objectives of the project should include: a) increasing the quantity and quality of information, by improving spatial resolution and increasing thematic diversity; b) improving the mobility of the information produced; and c) improving public participation in the decision making processes.

Integrating GIScience $[10,17]$ and information technologies in the decision making process, corresponds to a major step to better address land management issues. GIScience includes data collection and measurement, data capture, spatial statistics, data modelling and theories of spatial data, data structures, display, all analytical tools, and institutional, management and ethical issues [17], we can then underline a group of features that can integrate an EMS, empowering the outcome and help structuring all governance issues. In resume, an EMS should have: (i) a concrete group of indicators and goals; (ii) quality control methods, in order to ensure data coherence and liability; (iii) data systematic and structuring procedures; (iv) a group of studies, following data collection; (v) public discussions and reports related to specific as well as broad issues; and (vi) a decision making procedure that can be translated into management options. An EMS should then be a dynamic process that results in concrete measures for land planning and management, facilitating public participation in the decision making processes.

\section{References}

[1] Brown, D., Aspinall, R. \& Bennett, D., Landscape Models and Explanation in Landscape Ecology - a space for generative landscape science. The Professional Geographer, 58(4), pp. 369-382, 2006.

[2] Turner, M.G., Gardner, R.H. \& O'Neill, R.V., Landscape Ecology in theory and practice: pattern and process, Springer, New York, pp. 421, 2001.

[3] Naveh, Z., Landscape Ecology as an emerging branch of human ecosystem science. Advances in Ecological Research, ed. A. MacFadyen \& E.D. Ford, Academic Press, New York, pp. 189-237, 1982.

[4] Klepeis, P. \& Turner B.L., Integrated land history and global change science: the example of the southern Yucatan peninsular region project. Land Use Policy, 18, pp. 239-272, 2001.

[5] Southworth, J., Cumming, G., Marsik, M. \& Binford, M., Linking spatial and temporal variation at multiple scales in a heterogeneous landscape. The Professional Geographer, 58(4), pp. 406-420, 2006. 
[6] O'Neill, R.V., Hunsaker, C.T., Timmins, S.P., Jackson, B.L., Jones, K.B., Riitters, K.H. \& Wickham, J.D., Scale problems in reporting landscape pattern at the regional scale. Landscape Ecology, 11, pp. 169-180, 1996.

[7] Bouma, J., The role of soil science in the land use negotiation process. Soil Use and Management, 17, pp. 1-6, 2001.

[8] Young, K. \& Aspinall, R., Kaleidoscoping landscapes, shifting perspectives. The Professional Geographer, 58(4), pp. 436-447, 2006.

[9] Turner, M.G., Landscape Ecology: what is the state of science? Annual Review of Ecology and Systematics, 36, pp. 319-344, 2005.

[10] Goodchild, M.F., Geographic information science and systems for environmental management. Annual Review of Environment and Resources, 28, pp. 493-519, 2003.

[11] Matthews, R. \& Selman, P., Landscape as a focus for integrating human and environmental processes. Journal of Agricultural Economics, 57(2), pp. 199-212, 2006.

[12] Zhu, X., Aspinall, R. \& Healey, R., ILUDSS: a knowledge-based spatial decision support system for strategic land-use planning. Computers and Electronics in Agriculture, 15, pp. 279-301, 1996.

[13] Matthews, K., Sibbald, A. \& Craw, S., Implementation of a spatial decision support system for rural land use planning: integrating geographic information system and environmental models with search and optimisation algorithms. Computers and Electronics in Agriculture, 23, pp. 9-26, 1999.

[14] Jongman, R.H., Homogenisation and fragmentation of the European landscape: ecological consequences and solutions. Landscape and Urban Planning, 58, pp. 211-221, 2002.

[15] Hagedorn, K., Arzt, K. \& Peters, U., Institutional arrangements for environmental co-operatives: a conceptual framework. Co-operative Arrangements to Cope with Agri-environmental Problems, ed. K. Hagedorn, 2002.

[16] Gatzweiler, F., Central and Eastern European agriculture and environment: the challenges of governance at multiple levels. Sociologia Ruralis, 45(3), pp. 139-152, 2005.

[17] Goodchild, M.F., Geographical information science. International Journal of Geographical Information Systems, 6(1), pp. 31-45, 1992.

[18] Al-Kodnamy, K., Using visualization techniques for enhancing public participation in planning and design: processes, implementation and evaluation. Landscape and Urban Planning, 45, pp. 37-45, 1999.

[19] McClure, W., The rural town: designing for growth and sustainability. University of Idaho, Moscow, 1997.

[20] Sanoff, H., Designing with community participation. McGraw-Hill, New York, 1978.

[21] Sanoff, H., Visual research methods in design. Van Nostrand Reinhold, New York, 1991.

[22] Towers, G., Building democracy: community architecture in the inner cities. University College London Press, London, 1995. 
[23] Smith, H., The citizens guide to planning. Planner's Press, Chicago, 1993.

[24] Lant, C., Kraft, S., Beaulieu, J., Bennett, D., Loftus, T. \& Nicklow, J., Using GIS-based ecological-economic modeling to evaluate policies affecting agricultural watersheds. Ecological Economics, 55, pp. 467-484, 2005 .

[25] Joerin, F. \& Musy, A., Land management with GIS and multicriteria analysis. International Transactions in Operational Research, 7, pp. 6778, 2000.

[26] Kleijn, D., Berendsen, F., Smit, R., Gilissen, N., Smit, J., Brak, B. \& Groeneveld, R., Ecological effectiveness of agri-environment schemes in different agricultural landscapes in the Netherlands. Conservation Biology, 18(3), pp. 775-786, 2004.

[27] Bell, S., Fonseca, M. \& Motten, L., Linking restoration and landscape ecology. Restoration Ecology, 5(4), pp. 318-323, 1997.

[28] Price, M. \& Lewis, M., The reinvention of cultural geography. Annals of the Association of American Geographers, 83(1), pp. 1-17, 1993.

[29] Poore, B., The open black box: the role of the end-user in GIS integration. The Canadian Geographer, 47(1), pp. 62-74, 2003.

[30] Voinov, A. \& Constanza, R., Watershed management and the web. Journal of Environmental Management, 56, pp. 231-245, 1999.

[31] Oliveira, D., Alonso, J., Santos, S., Rocha, J. e Guerra, C., Integrated Watershed Planning and Management: Methodology for the assessment of water quality under Eucalyptus (Eucalyptus globulus Labill.); International IUFRO Conference of the WP2.08.03 on Silviculture and Improvement of Eucalypts, 11-15 October, Aveiro, Portugal, 2004.

[32] Alonso, J.; Rey, J.; Santos, S.; Paredes, C., Estudos de Casos de Boas Práticas Ambientais na Agricultura, Manual de Agricultura e Ambiente, Sociedade Portuguesa de Inovação, 2005.

[33] Costa, L.; Costa, A.; Esteves, A.; Valente, A.; Fernandes, F.; Gonçalves, F.; Rodrigues, G.; Alonso, J.; Araújo, J.; Sousa, M.; Pereira, S.; Mendes, V., Proposta de Plano de Gestão e de Ordenamento da Paisagem Protegida das Lagoas de Bertiandos e S. Pedro D’Arcos. Ponte de Lima, 2001.

[34] Alonso, J.; Rey-Graña, J.; Santos, S.; Paredes, C:, e Vasconcelos, I., Sistema de Informação Geográfica para a Paisagem Protegida das Lagoas de Bertiandos e S. Pedro d'Arcos (SIG@PPLBSPA). Instituto Politécnico de Viana do Castelo (IPVC); Escola Superior Agrária de Ponte de Lima (ESAPL), pp. 56, 2002. 